\title{
South Africa: Integrating services for FP and HIV improves quality and HIV testing
}

Population Council

Follow this and additional works at: https://knowledgecommons.popcouncil.org/departments_sbsr-rh

Part of the Demography, Population, and Ecology Commons, Family, Life Course, and Society Commons, Gender and Sexuality Commons, International Public Health Commons, Maternal and Child Health Commons, Medicine and Health Commons, and the Women's Health Commons How does access to this work benefit you? Let us know!

\section{Recommended Citation}

"South Africa: Integrating services for FP and HIV improves quality and HIV testing," FRONTIERS OR Summary. Washington, DC: Population Council, 2008. 
South Africa
Integration

OR Summary 79

\section{Integrating Family Planning and HIV Services Improves Service Quality}

Two models of integrating routine provider-initiated counseling and testing for HIV with family planning services were feasible and acceptable to South African clients and providers and did not compromise quality of care. In a second phase, the intervention will be expanded to two additional provinces.

\section{Background}

The South African government wishes to expand the availability and use of counseling and testing (C\&T) for HIV. One option is to integrate C\&T into well-attended services, such as family planning (FP). In 2004, as part of that effort, the Population Council began a three-year study with the Department of Health (DOH) in North West Province.

The study tested the feasibility, acceptability, and cost of two models for integrating HIV prevention services, including C\&T, within established FP programs, and evaluated their quality against the standard practice.

Eighteen FP clinics in North West Province were randomized into testing, referral, and control groups, with six clinics in each group. In the testing-model clinics, providers offered and provided C\&T services at the same consultation; in the referral-model clinics, providers offered HIV counseling and referred clients to the VCT services for testing in the same clinic or a nearby one offering those services.

A total of 129 providers from the 12 experimental clinics were trained to give information and counseling on family planning, risks and prevention of HIV and sexually transmitted infections (STIs), and condom use for dual protection against pregnancy and STIs. All providers were trained to use the Balanced Counseling Strategy Plus toolkit ( $B C S+$ ), adapted to integrate counseling on prevention of STIs and HIV. ${ }^{1}$ In the testing model, providers also received training in rapid HIV testing and pre- and post-test counseling. In the control clinics, providers gave standard care to FP clients as stipulated in the Primary Health Care package in the public sector.

Researchers assessed the intervention's impact through pre- and post-intervention interviews, focus group discussions with providers and clients, observation of client-provider interactions, and client exit interviews at intervention and control clinics. Scores measuring quality of care reflected changes in 30 indicators on four counseling categories (FP, STI prevention, dual protection, and C\&T) and on client-provider interactions.

\section{Findings}

- Overall, integrating HIV C\&T into FP was feasible and acceptable to clients and providers with no difference between the models.

- The quality of counseling improved in both intervention models in all indicator categories. The

\footnotetext{
${ }^{1}$ The BCS is an algorithm for helping clients identify appropriate FP methods. The BCS + is a modification to include counseling and information on HIV and STIs and their prevention during the FP counseling. Online at: http://www.popcouncil.org/frontiers/bestpractices/BCSPlus_102008.html
} 
greater improvement occurred in the referral-model clinics, where significant improvements occurred in 23 of the 30 indicators, compared with 12 of 30 indicators in the testing model. In the control clinics, significant improvement occurred only in the indicators for dual protection counseling, which may reflect nationwide efforts to promote condom use for HIV prevention. Client-provider interactions were of high quality at baseline and made significant gains only in the referral model.

\section{- The proportion of providers mentioning C\&T} services doubled in the intervention clinics, which led to significant increases in the proportion of clients who accepted testing (see Table 1). Mentioning and offering HIV C\&T is clearly feasible and acceptable, and greater emphasis on offering testing would lead to even higher levels of testing.

- Use of the BCS+ materials (in $32 \%$ of consultations in the testing model and $61 \%$ in the referral model) increased the likelihood that providers would offer C\&T, and that the offer would be accepted. Nearly all providers who used the algorithm, the cards, or both $(94 \%, 97 \%$, and $96 \%$, respectively) mentioned C\&T, compared to 65 percent when no materials were used. Over 80 percent of providers who used the $\mathrm{BCS}+$ materials discussed STI risk factors, compared to 59 percent when no materials were used.

- Between baseline and endline, the proportion of clients using condoms along with another contraceptive method increased significantly (from $10 \%$ or less to between $35 \%$ and $50 \%$ ). Significant increases also occurred in clients reporting condom use during the last month (from 13\% to $24 \%$ in the testing model) and in clients who had ever had an HIV test (28\% to 39\% in the referral model); control sites showed a decrease in these two indicators at endline.

- Average training costs per provider were similar in the two models (US\$559 in the testing model and \$514 in the referral model). Changes to service costs would vary according to clinic attendance in a given year and the type and volume of testing carried out.

\section{Utilization}

- The Population Council, with support from PEPFAR/ South Africa, is responding to a request from the National Department of Health to scale up these models within North West Province and to introduce them into an additional two provinces. Either integration model can be used depending on what is feasible for individual clinics and districts.

\section{Policy Implications}

- Both integration models provide a way forward in implementing the government policy of offering C\&T to all clients seeking reproductive health services. Efforts to integrate services need to be combined with initiatives to emphasize the need to change risky sexual behavior.

Source: Mullick, Saiqa et al. Feasibility, effectiveness and cost of models of integrating counseling and testing for HIV within family planning services in South Africa," FRONTIERS Final Report. Washington, DC: Population Council. Available on our website at www. popcouncil.org/frontiers or by e-mail: publications@popcouncil.org

This publication is made possible by the generous support of the American people through the President's Emergency Fund for AIDS Relief, the United States Agency for International Development (USAID) under the terms of Cooperative Agreement No. HRN-A-00-98-00012-00, and USAID Cooperative Agreement No. 674-A-00-08-00002-00 for South Africa ASSIST Umbrella Grants Management Program, Academy of Educational Development Grant No. 3828-00-Popcounc-01. The contents are the responsibility of the FRONTIERS Program and do not necessarily reflect the views of USAID or the United States Government.

\section{Population Council}

